\title{
70 DEVELOPMENT OF A BLIND HOLE SUBSTRATE SLOTTED MICROSTRIP ANTENNA FOR X-BAND APPLICATIONS
}

\author{
Aminu Atiku Shehu ${ }^{1}$, Zainab Yunusa ${ }^{1}$, Mohd Nizar Hamidon², Abdullahi Auwal Gabari2, Zainab Umar \\ Sani $^{2}$ \\ E-Mail Id: aashehu@gmail.com, zee2yunusa@gmail.com \\ ${ }^{1}$ Department of Electrical Engineering, Bayero University Kano, Nigeria \\ ${ }^{2}$ Institute of Advanced Technology, University Putra Malaysia, Selangor, Malaysia
}

\begin{abstract}
This paper is aimed at developing a blind hole substrate slotted microstrip patch antenna for x-band applications. The proposed antenna has been designed using Roggers RT5880 (lossy) substrate of dielectric constant of 2.2 sandwiched between copper patch and ground plane. The propounded antenna has been devised and simulated in CST Microwave Studio 2014. This antenna resonates at frequency of $10.45 \mathrm{GHz}$ with the minimal return loss of $55.30 \mathrm{~dB}$, high gain of $8.02 \mathrm{~dB}$ and directivity of $8.50 \mathrm{dBi}$. The proposed antenna works for all frequencies from $8-$ $12 \mathrm{GHz}$ resulting in a huge bandwidth of $1.1 \mathrm{GHz}(9.99 \mathrm{GHz}-11.09 \mathrm{GHz})$. Bandwidth enhancement of 50 percent is observed in the proposed antenna as compared to the existing antenna. The proposed antenna provides this huge bandwidth with a compact size. The designed antenna can be suitably employed for all X-Band (8-12 GHz) applications including Radar and satellite communications, weather monitoring, military communications, satellite to earth downlink, earth to satellite uplink, radio determination and ultra-wide band applications.

Index Terms- blind hole substrate; huge bandwidth; high gain; Earth-satellite uplink; Satellite-earth downlink; Xband; wide-band antenna and slot
\end{abstract}

\section{INTRODUCTION}

In recent years, wireless communication has been gradually developing and involving innovative wants in antenna technology. Wireless communication has so many applications like WLAN, WIFI, mobile phone, satellite, traffic radar, GPS, military, biomedical and aerospace area that antenna structure is vital part of these systems. Antenna plays the key role of wireless communication from point to the other; it acts as the transducer where it transforms the electrical signal to radio waves, which also helps in conveying the information.

The microstrip antenna (MPA) has been said to be the most innovative area in the antenna engineering. The idea of microstrip antenna was first presented in year 1950s but it only got serious attention in the 1970s. The exceptional features that made the microstrip antenna prominent are relatively easy to construct, light in weight, low in cost and extremely thin protrusion from the surface. These MPAs have a popular frequencies range of above $100 \mathrm{MHz}$. This patch antenna is actually fabricated on a dielectric substrate. The advantage of having this conformable structure is to integrate into various telecommunication systems [1].

The principle of wide bandwidth or bandwidth enhancement of MPAs may be achieved by several efficient approaches such as: Increasing the substrate thickness, Optimizing impedance matching, Reduce substrate effective permittivity, incorporating multiple resonances. In this work a slot creation on the ground elements is utilized to achieve wider bandwidth. Some recent works has been summarized in the Table 1 so as to review the literature and highlight research gap. The summary was presented based on the performance indicators for characterization in terms of antenna gain and bandwidth. Generally, the main limitation of microstrip patch antenna includes low gain and narrow bandwidth. However, some of the already published works in this field include [1-15].

In 2014, a wide band microstrip antenna is designed for Ku band applications with defected ground structure; a circular shape defect is integrated in the ground plane [1]. In the same year, a paper investigate the dependency of antenna parameters designed for $10 \mathrm{GHz}$ inset fed rectangular microstrip patch antenna (RMPA) on varying inset width and inset gap for proper impedance matching so as to have minimum return loss and achieve efficient operation [2]. Also in 2014, a comparative performance study of rectangular and circular shape microstrip patch antennas at an X band frequency, circular patch antenna offers about eight percent higher bandwidth and nearly $2.0 \mathrm{~dB}$ less side lobe power than that of rectangular patch antenna [3]. Later in 2015, a coaxial probe feed modified swastika shape patch antenna is designed and analyzed to obtain the broadband frequency range in X-band (8-12 GHz) [4]. Also in the same year, a slotted fan shaped microstrip patch antenna with three operating frequencies for radar application is presented; the design model is made to resonate at three frequencies in X-band [5]. In the same year, a Microstrip Patch antenna for radar application is presented, in this paper, conventional shapes like rectangular, triangular and circular microstrip Patch antenna are designed and analyzed at X-band frequency [6]. Also in 2016, a design of a high gain and directivity blind hole substrate slotted microstrip patch antenna for X-band applications was done, the anticipated antenna resonates at frequency of $7.94 \mathrm{GHz}$ with the minimal return loss of $-81.25 \mathrm{~dB}$, high gain of $8.5 \mathrm{~dB}$ and directivity of DOI Number: https://doi.org/10.30780/IJTRS.V04.I12.002

pg. 10

$$
\begin{aligned}
& \text { www.ijtrs.com } \\
& \text { www.ijtrs.org }
\end{aligned}
$$




\section{International Journal of Technical Research \& Science}

$8.12 \mathrm{dBi}$ with a limited bandwidth; this thesis is aimed at improving [7, 8]. In the same year, a method has been proposed to simultaneously enhance the gain and bandwidth of a microstrip patch antenna [9]. The same year; a design of both planar ultra-wide band (UWB) antenna and UWB antenna with two rejected bands are given, the rejected bands are the WLAN and X-bands, achieved by inserting slots in the patch and the feed [10]. Also in 2016, Also, a novel design of multiband microstrip patch antenna which resonate at 7 unique frequencies between $4 \mathrm{GHz}$ and 14 $\mathrm{GHz}$ by inserting a rectangular slot in the ground plane of the patch antenna [11]. Later in 2017, a design of Microstrip Patch Antenna (MPA) using hybrid fractal slot (Koch-Minkowski and Koch-Koch) along with partial ground plane for wideband applications with two resonant frequencies, good gain and bandwidth [12]. In the same year, a combined and compact double $\mathrm{H}$-shaped $\mathrm{X}$-band microstrip patch antenna is designed for bandwidth enhancement [13]. Also the same year, a Hexagonal Patch Microstrip antenna for C Band, X Band and Ku Band Applications with partial and slotted ground plane resulting in a huge bandwidth enhancement of 504 percent [14]. In the same year, a Multiband rectangular shaped Microstrip patch antenna is designed using coaxial feeding techniques which can be used in C \& $\mathrm{X}$ Band applications [15]. Therefore a small size antenna with a wider bandwidth has been proposed in this work.

Table-1.1 Literiture Mapping

\begin{tabular}{|c|c|c|c|c|c|}
\hline Author & $\begin{array}{c}\text { Substrate Type / } \\
\text { Software }\end{array}$ & $\begin{array}{c}\text { Resonant } \\
\text { Frequency (GHz) }\end{array}$ & $\begin{array}{c}\text { Bandwidth (MHz } \\
\text { / \%) }\end{array}$ & Gain(dB) & $\begin{array}{c}\text { Antenna } \\
\text { Size(mm }\end{array}$ \\
\hline Mukesh et al, 2014 [1] & FR4 / HFSS & 9.8 & 56.6 & $5-12.88$ & $36 \times 36 \times 0.762$ \\
\hline Vinayak et al, 2014 [2] & FR4 & 10 & $5-8$ & $5.5-6$ & $48 \times 18.12 \times 1.5$ \\
\hline Tahsin et al, 2014 [3] & DUROID & 10 & 1.04 & $7.7-7.9$ & $8.8 \times 9.95 \times 1.57$ \\
\hline Vivek et al, 2015 [4] & FR4 / HFSS & 9.5 & $16.4-17.89$ & $4.22-4.6$ & $30 \times 30 \times 3$ \\
\hline Kiruthika et al, 2016 [5] & FR4 / HFSS & 9.9 & 9.5 & $1.17-3.33$ & $31.31 \times 28.33 \times 1.6$ \\
\hline Kiruthika et al, 2016 [6] & FR4/HFSS & 9.5 & $453-488$ & $3.67-4.31$ & $18.72 \times 16.02 \times 1.6$ \\
\hline $\begin{array}{c}\text { Divesh et al, 2016 [7] } \\
\text { FR4 / CST }\end{array}$ & 7.9 & 560 & 8.5 & $17.15 \times 33.97 \times 1.57$ \\
\hline $\begin{array}{c}\text { Divesh et al, 2016 [8] } \\
\text { [9] aR4 / CST }\end{array}$ & 7.9 & 560 & 8.5 & $17.15 \times 33.97 \times 1.57$ \\
\hline $\begin{array}{c}\text { Muhammad et al, 2016 } \\
\text { DUROID / FR4 }\end{array}$ & 60 & $384-1228$ & $13.53-$ & $4.44 \times 5.54 \times 0.13$ \\
\hline Noor et al, 2016 [10] & FR4 / HFSS & & & 6.1 & $30 \times 35 \times 1.6$ \\
\hline Prema et al, 2016 [11] & FR3.5 / CST & $4.5-12.6$ & & 6.76 & $55 \times 40 \times 25$ \\
\hline $\begin{array}{c}\text { Narinder et al, 2017 } \\
\text { [12] }\end{array}$ & FR4 / CST & 3.2 & $2440-2660$ & $5.6-6.1$ & $45 \times 39 \times 1.6$ \\
\hline $\begin{array}{c}\text { Jubear et al, 2017 [13] } \\
\text { [14] }\end{array}$ & FR4 / CST & 10 & & 5.29 & $18 \times 20 \times 1.6$ \\
\hline $\begin{array}{c}\text { Shailendra et al, 2017 } \\
\text { Angelin et al, 2017 [15] }\end{array}$ & FR4 / CST & $3.68-18.3$ & $504 \%$ & 4.5 & $15 \times 20 \times 1.6$ \\
\hline
\end{tabular}

\section{METHODOLOGY}

\subsection{Mathematical Formulation of Patch Antenna}

A microstrip patch antenna can be conventionally designed using the following equations given empirically by [16] as:

$$
\Delta L=0.412 h \frac{\left(\varepsilon_{e f f}+0.3\right)\left(\frac{W}{h}+0.264\right)}{\left(\varepsilon_{e f f}-0.258\right)\left(\frac{W}{h}+0.8\right)}
$$

DOI Number: https://doi.org/10.30780/IJTRS.V04.I12.002

pg. 11

www.ijtrs.com

www.ijtrs.org 


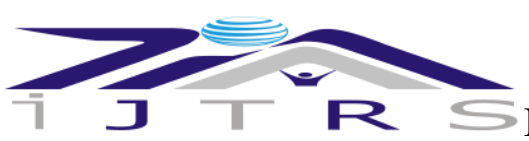

Where $\mathrm{h}$ is the substrate thickness and $\mathrm{W}$ is the width of the patch. The effective length of the patch $\mathrm{L}_{\mathrm{eff}}$ now becomes: $L_{\text {eff }}=L+2 \Delta L$

Where, $L$ is the patch length.

For a given resonance frequency, $f_{o}$ the effective length of the patch is given by as:

$L_{e f f}=\frac{c}{2 f_{o \sqrt{\varepsilon_{e f f}}}}$

For a rectangular patch antenna, the resonance frequency is given by [17] as:

$f_{o}=\frac{c}{2 \sqrt{\varepsilon_{e f f}}}\left[\left(\frac{m}{L}\right)^{2}+\left(\frac{n}{W}\right)^{2}\right]^{2}$

The $\mathrm{m}$ and $\mathrm{n}$ are modes along $\mathrm{L}$ and $\mathrm{W}$ while $\mathrm{W}$ is the width of the patch given by [17] as in equation 5 .

$W=\frac{c}{2 f_{o} \sqrt{\frac{\varepsilon_{r}+1}{2}}}$

\subsection{Design of the Antenna}

The design of this microstrip patch antenna based on the equations 1 to 5 of the transmission and the cavity model of microstrip patch antenna. The substrate that was used is RT 5880 and the dimensions of the substrate and the patch are presented in Table 2.2.

\begin{tabular}{|c|l|l|}
\multicolumn{2}{c}{ Table-2.2 Antenna Design Parameters } \\
\hline S. No. & Parameters & Dimensions \\
\hline 1 & Ground thickness & 0.02 \\
\hline 2 & Patch thickness & 0.13 \\
\hline 3 & Substrate thickness & 1.57 \\
\hline 4 & Feed length & 2.00 \\
\hline 5 & Patch length & 7.73 \\
\hline 6 & Substrate length & 17.15 \\
\hline 7 & Slot length & 6.00 \\
\hline 8 & Feed width & 5.58 \\
\hline 9 & Slot width & 2.00 \\
\hline 10 & Patch width & 0.84 \\
\hline 11 & Substrate width & 2.28 \\
\hline 12 & Blind hole diameter & 2.00 \\
\hline 13 & Blind hole depth & 1.00 \\
\hline 14 & $\begin{array}{l}\text { Distance of blind hole from } \\
\text { left }\end{array}$ & 1.99 \\
\hline 15 & $\begin{array}{l}\text { Distance of blind hole from } \\
\text { top }\end{array}$ & 8.56 \\
\hline
\end{tabular}

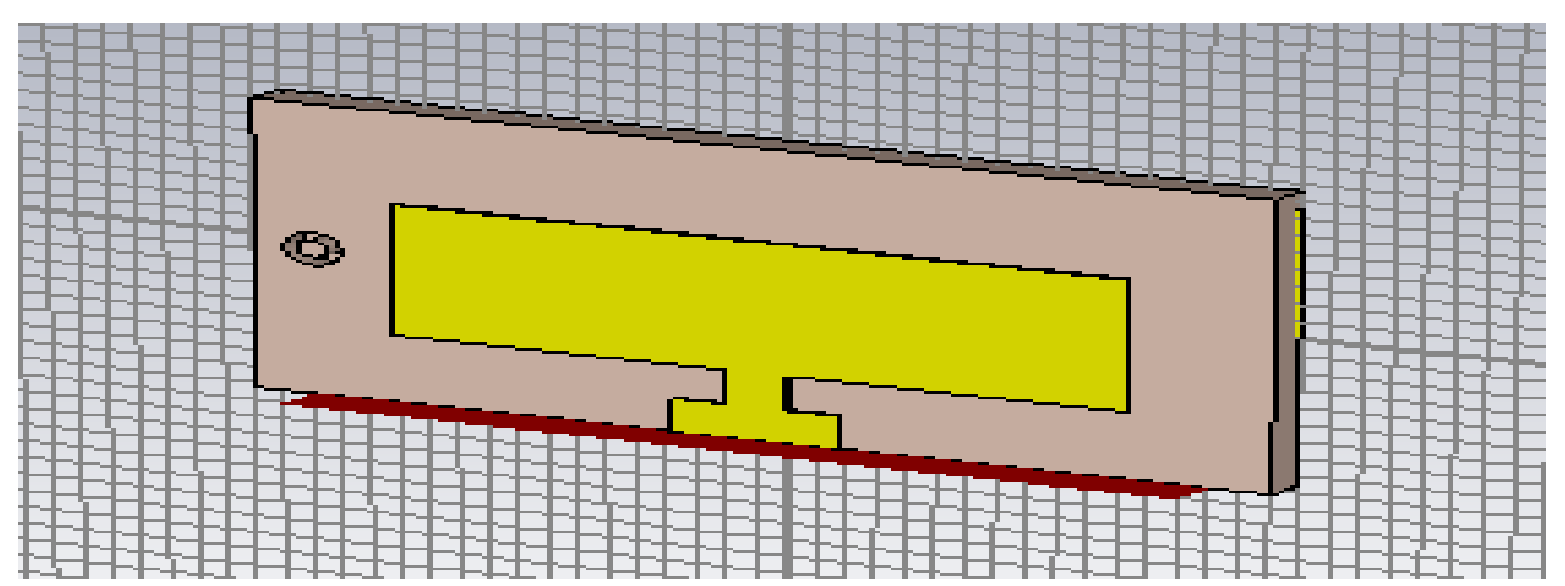

Fig. 2.1 Design of Microstrip Patch Antenna in CST View (front)

DOI Number: https://doi.org/10.30780/IJTRS.V04.I12.002

pg. 12

www.ijtrs.com

www.ijtrs.org 


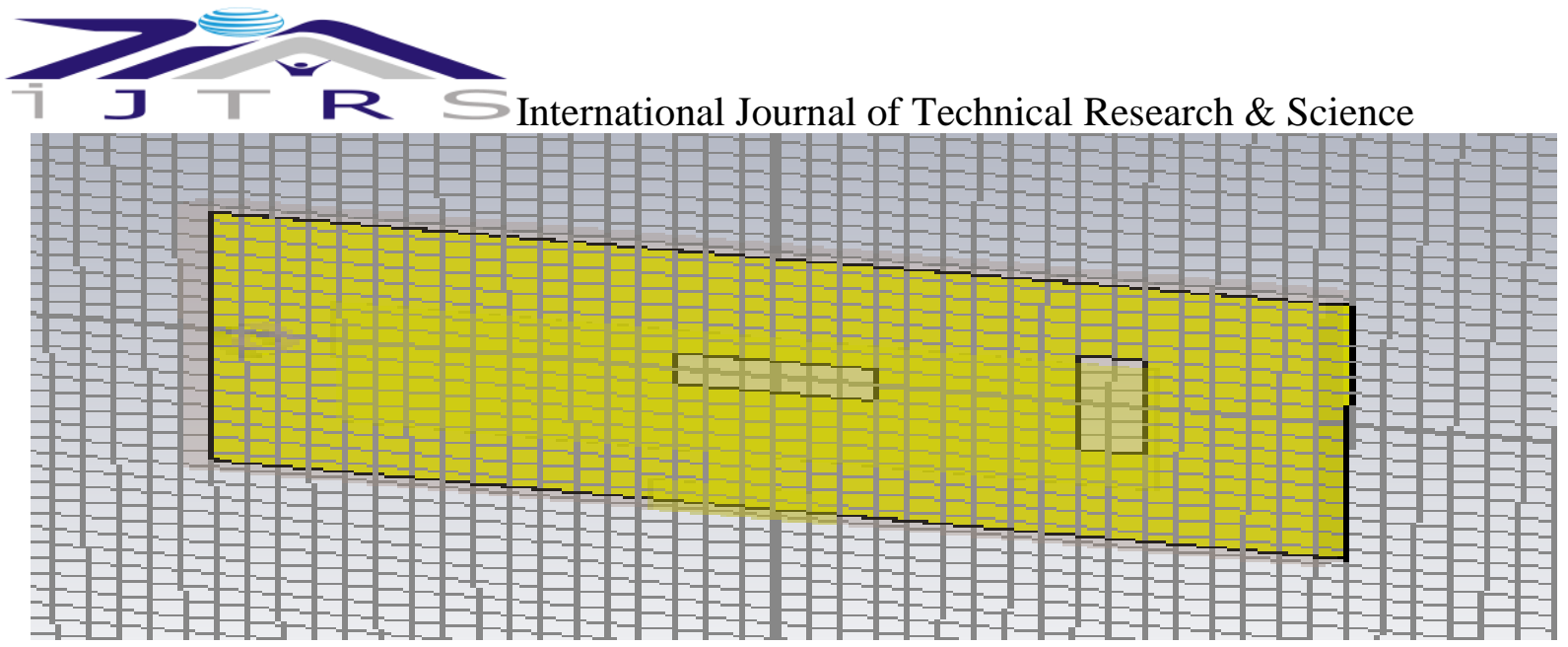

Fig. 2.2 Design of Microstrip Patch Antenna in CST View (back)

\section{RESULTS AND DISCUSSIONS}

The antenna was modeled and simulated using CST studio wave and each layer of the proposed design was assigned with its respective physical and electrical properties. The result of the return loss, VSWR (Voltage Standing Wave Ratio), gain and the radiation pattern of the array patch elements obtained is shown in Figure 3.1-3.3. The patch antenna resonates at $10.45 \mathrm{GHz}$ with a return loss of $-55.3 \mathrm{~dB}$ as seen in Figure 3 below. The acceptable level of VSWR for wireless application should be less than 2 and as seen in Fig. 3.3, the VSWR of the single patch antenna is 1.00 . The antenna achieved a high gain of $8.02 \mathrm{~dB}$ with bandwidth of $1.1 \mathrm{GHz}$ that span from $9.99 \mathrm{GHz}$ to 11.09 $\mathrm{GHz}$ of mm-wave band which is considered excellent in terms of a compact microstrip patch antenna as shown in Fig 3.1. Also as shown in table 2.2, the antenna size is very small of the precise dimension of $17.15 \mathrm{~mm}$ by $33.97 \mathrm{~mm}$ by $1.57 \mathrm{~mm}$. The summary of the performance measure of the antenna in terms of gain, return loss, VSWR, and bandwidth were summarized in the Table 3.1.

\begin{tabular}{|l|c|c|}
\hline S. No. & Pable-3.1 Summary of Results & Value \\
\hline 1 & Return Loss (dB) & -55.3 \\
\hline 2 & Bandwidth $(\mathrm{GHz})$ & 1.10 \\
\hline 3 & VSWR & 1.00 \\
\hline 4 & Gain (dB) & 8.02 \\
\hline
\end{tabular}

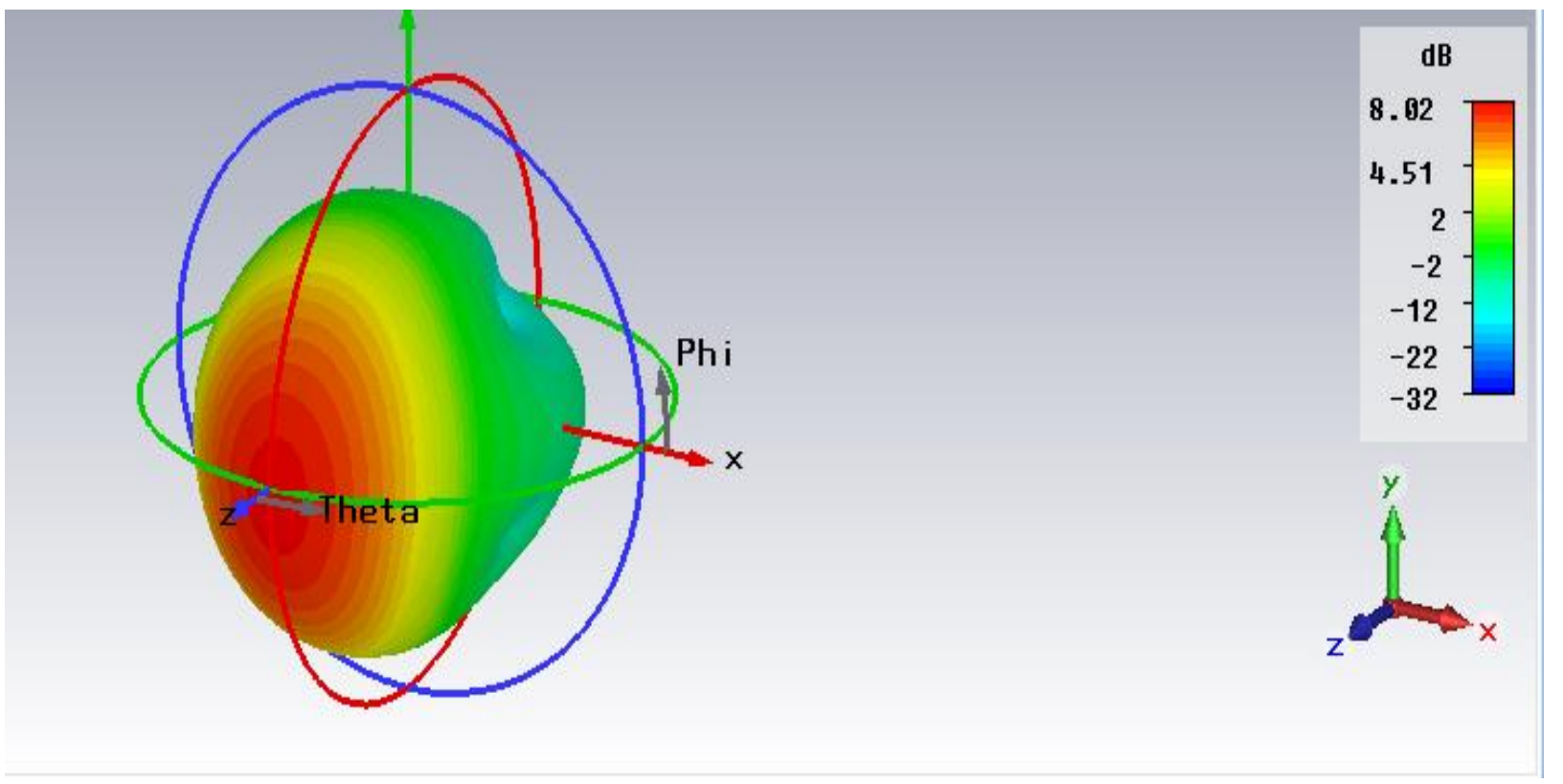

Fig. 3.1 Gain of Microstip Patch Antenna 


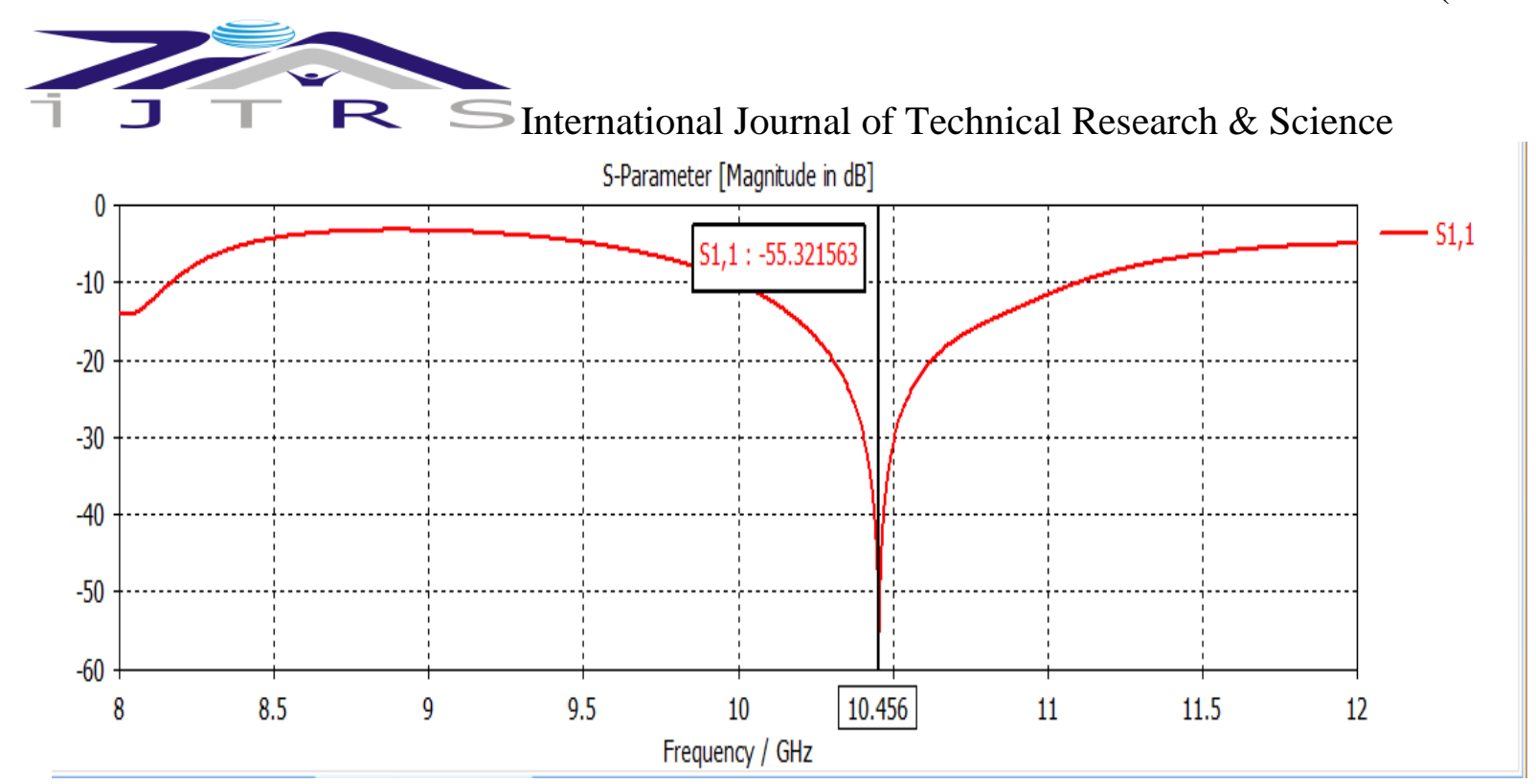

Fig. 3.2 Return Loss of Microstrip Patch Antenna

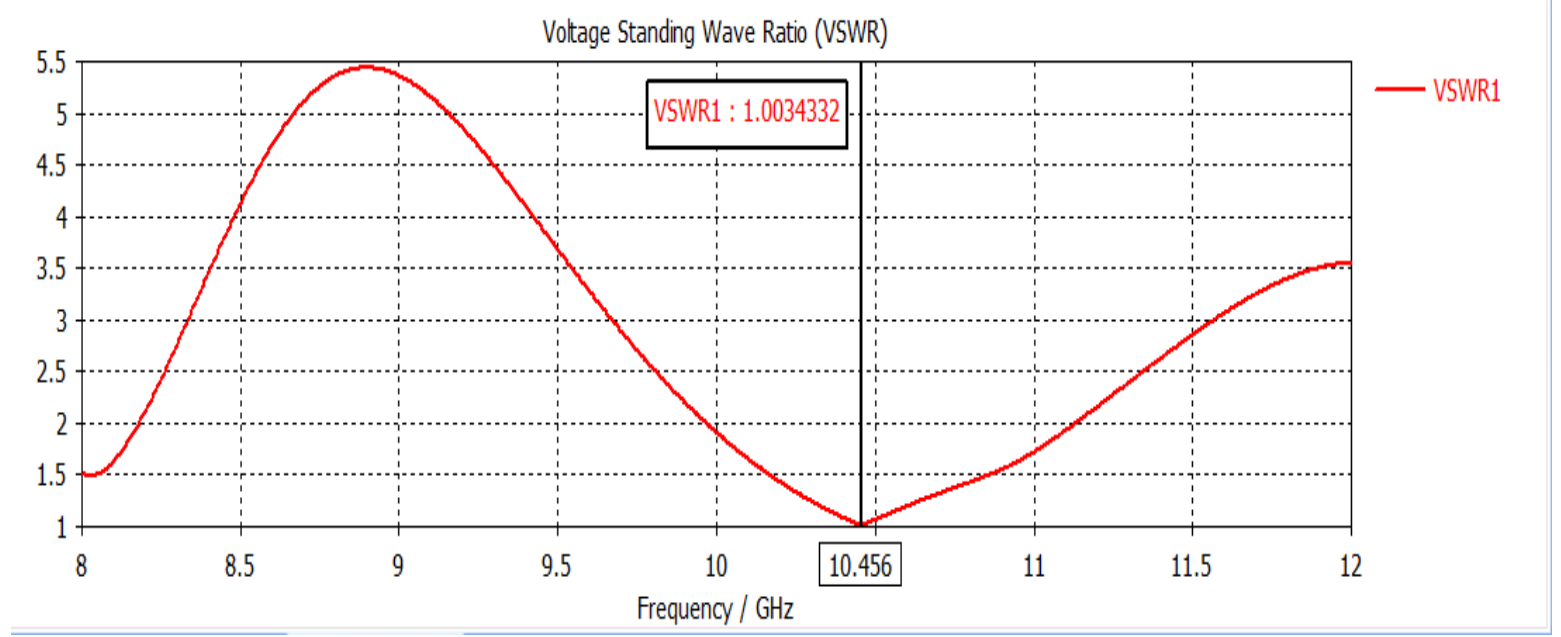

Fig. 3.3 VSWR of Microstrip Patch Antenna

The performance indicators for the antenna are summarized in Table 3.2 to highlight the contribution of this work. It could be observed from Table 5 that there is improvement in terms of bandwidth from $0.56 \mathrm{GHz}$ to $1.10 \mathrm{GHz}$ but the gain of the proposed work is $8.02 \mathrm{~dB}$, which is a little less than that of the existing work. This is usually the case in antenna design of a usual trade-off between gain and bandwidth.

Table-3.2 Comparison of Proposed Work With the Existing

\begin{tabular}{|l|c|c|}
\hline Parameter & Proposed Work & Existing Work \\
\hline Bandwidth $(\mathrm{GHz})$ & 1.10 & 0.56 \\
\hline VSWR & 1.00 & 1.7 \\
\hline Return Loss $(\mathrm{dB})$ & -55.3 & -81.3 \\
\hline Gain $(\mathrm{dB})$ & 8.02 & 8.50 \\
\hline
\end{tabular}

\section{CONCLUSION}

The proposed antenna shows good results in terms of bandwidth. A huge increment of $100 \%$ is observed in the proposed antenna. The proposed antenna covers the X- band satellite communication applications. The specified frequency ranges can also be employed for military satellite, military and government institutions for weather monitoring, air traffic control, maritime vessel traffic control, radio-determination purposes, defense and tracking vehicle speed detection for law enforcement. Further work will be the fabrication of the simulated design to validate the results.

DOI Number: https://doi.org/10.30780/IJTRS.V04.I12.002

pg. 14

www.ijtrs.com

www.ijtrs.org 


\section{J}

\section{REFERENCES}

[1] Mukesh Kumar "Analysis and design of wide band Microstrip-line-fed antenna with defected ground structure for Ku band applications", International Journal of Electronics and Communications (AEU) 68 (2014) 951-957.

[2] Vinayak Samarthay "Designing and Optimization of Inset Fed Rectangular Microstrip Patch Antenna (RMPA) for Varying Inset Gap and Inset Length", International Journal of Electronic and Electrical Engineering. ISSN 0974-2174 Volume 7, Number 9 (2014), pp. 1007-1013.

[3] Tahsin Ferdous "Comparative Study of Rectangular and Circular Microstrip Patch Antennas in X Band", International Conference on Electrical Engineering and Information \& Communication Technology (ICEEICT) 2014.

[4] Vivek Singh “A Compact and Wide Band Microstrip Patch Antenna for X-Band Applications", 2015 Second International Conference on Advances in Computing and Communication Engineering.

[5] R. Kiruthika "A Fan Shaped Triple Band Microstrip Patch Antenna with DGS for X-band Applications", 2016 International Conference on Control, Instrumentation, Communication and Computational Technologies (ICCICCT).

[6] R. Kiruthika "Comparison of Different Shapes in Microstrip Patch Antenna for X-band Applications", 2016 International Conference on Emerging Technological Trends [ICETT].

[7] Divesh Mittal "High Gain Blind Hole Substrate Slotted Microstrip Patch Antenna Design for X-Band Applications", 2016 International Conference on Automatic Control and Dynamic Optimization Techniques (ICACDOT).

[8] Divesh Mittal "High Directivity FR4 Substrate Slotted Defected Ground Microstrip Patch Antenna for X-Band Applications", 2016 International Conference on Global Trends in Signal Processing, Information Computing and Communication.

[9] Muhammad Saqib "Improvement of microstrip patch antenna gain and bandwidth at $60 \mathrm{GHz}$ and X bands for wireless applications", The Institution of Engineering and Technology (IET) Microwave Antennas Propagation, 2016, Vol. 10, Iss. 11, pp. 1167-1173.

[10] Noor M. Awad "Multislot microstrip antenna for ultra wide band applications", Journal of King Saud University - Engineering Sciences (2016).

[11]N. Prema "Design of multiband microstrip patch antenna for C and X band", Optik 127 (2016) 8812-8818. http://dx.doi.org/10.1016/

[12] Narinder Sharma "A design of Microstrip Patch Antenna using hybrid fractal slot for wideband applications", Ain Shams Engineering Journal 2017.

[13] Md. Jubaer Alam “A Combined Double H-shaped Microstrip Patch Antenna for X-Band operation”, International Conference on Electrical, Computer and Communication Engineering (ECCE), February 2017.

[14] Shailendra Kumar "A Hexagonal Broadband Compact Microstrip Monopole Antenna for C Band, X Band and $\mathrm{Ku}$ Band Applications", International Conference on Computing, Communication and Automation (ICCCA2017).

[15] Angelin Immagulate "Design and Analysis of Multiband Microstrip Antenna using Coaxial Feed for C \& XBand", 2017 International Conference on circuits Power and Computing Technologies [ICCPCT].

[16]Zhang B., Zhang Y. P., Titz D., Ferrero F., and Luxey C., "A circularly-polarized array antenna using linearlypolarized sub grid arrays for highly-integrated 60-GHz radio", IEEE Trans. Antennas Propag., vol. 61, 2013, no. 1, pp. 436-439.

[17] James, J.R., Hall, P. S. (eds.), "Handbook of Microstrip Antennas”, Peter Peregrinus Ltd. (London) on behalf of the IEE, vol. 1 \& 2, 1989. 